\title{
Avaliação das Habilidades Metafonológicas (PROHFON): Caracterização e Comparação do Desempenho em Escolares
}

\author{
Metalinguistic Skills Evaluation (PROHFON): Characterization and Comparison \\ of Students' Performance
}

\author{
Giseli Donadon Germano* \& Simone Aparecida Capellini \\ Universidade Estadual Paulista Júlio de Mesquita Filho, Marília, SP, Brasil
}

\begin{abstract}
Resumo
Este estudo teve como objetivos caracterizar e comparar o desempenho de escolares com bom desempenho acadêmico do $3^{\circ}$ ao $6^{\circ}$ ano do Ensino Fundamental I e II nas Provas de Habilidades Metafonológicas (PROHFON). Participaram 169 escolares do $3^{\circ}$ ao $6^{\circ}$ ano do ensino fundamental, de ambos os gêneros, com faixa etária entre sete e 13 anos de idade, divididos grupos (GI: 52 escolares do $3^{\circ}$ ano; GII: 51 escolares do $4^{\circ}$ ano; GIII: 42 escolares do $5^{\circ}$ ano; GIV: 24 escolares do $6^{\circ}$ ano). Os resultados deste estudo demonstraram que os escolares, independente da seriação escolar, apresentaram dificuldades principalmente nas habilidades fonêmicas de contagem, de síntese e análise e na habilidade suprassegmental (rima). Concluímos que o PROHFON possibilitou a caracterização e a comparação dos escolares com bom desempenho acadêmico, sendo que não foram todas as habilidades metafonológicas que os escolares deste estudo apresentaram domínio de acordo com o aumento da escolarização, sugerindo falha no domínio das competências necessárias para a aquisição do principio alfabético da Língua Portuguesa.

Palavras-chave: Avaliação, educação, leitura, Fonologia.
\end{abstract}

\begin{abstract}
This study aimed to characterize and to compare the performance of students with good academic performance from $3^{\text {rd }}$ to $6^{\text {th }}$ grade of Fundamental Education I and II in Metalinguistic Skills Tests (PROHFON). The study was composed of a total of 169 students from $3^{\text {rd }}$ to $6^{\text {th }}$ grade, of both genders, aged between 7 and 13 years, divided into two groups (GI: 52 students from $3^{\text {rd }}$ grade; GII: 51 students from $4^{\text {th }}$ grade; GIII: 42 students from $5^{\text {th }}$ grade; GIV: 24 students from $6^{\text {th }}$ grade). Results showed that students, regardless of their progress across grades, presented difficulties particularly in phonemic abilities of count, synthesis and analysis and the suprassegmental skills (rhyme). We concluded that PROHFON allowed for the characterization and comparison of students with good academic performance, and the students in this study did not present full domain in all metalinguistic skills as they progressed through grades, suggesting failure in the mastery of skills necessary for the acquisition of the alphabetic principle of the Portuguese language.

Keywords: Evaluation, education, reading, Phonology.
\end{abstract}

A relação entre a consciência fonológica, a leitura e a escrita vem sendo documentada pela literatura há pelo menos 30 anos. O pressuposto de que, em sistemas alfabéticos, a aprendizagem de habilidades como a leitura e a escrita implica uma reflexão deliberada da fala, a fim de que esta se torne objeto de sua atenção consciente e possibilite o desenvolvimento da consciência metalinguística, tem sido um consenso entre diversos autores (Bradley \& Bryant, 1983; Hayes \& Slater, 2008; Manz, Hughs, Barnabas, \& Bracaliello, 2010).

Estudos referiram que o desenvolvimento das habilidades fonológicas ocorre em progressão, iniciando logo

*Endereço para correspondência: Universidade Estadual Paulista Júlio de Mesquita Filho, Faculdade de Filosofia e Ciências, Departamento de Fonoaudiologia, Av. Hygino Muzzy Filho, 737, Marília, SP, Brasil 17525-900. E-mail: giseliger@yahoo.com.bre sacap@uol.com.br nos primeiros meses de vida da criança até o ingresso na aprendizagem da leitura e escrita nos primeiros anos escolares (Cervera-Mérida \& Ygual-Fernández, 2003; Chard \& Dickson, 1999; Gombert, 2003), sendo que a percepção de que a fala possui uma estrutura fonêmica subjacente é essencial para a aquisição da leitura, pois tal estrutura possibilita utilizar um sistema gerativo que converte a ortografia em fonologia (Hayes \& Slater, 2008; Manz et al., 2010).

Deste modo, para que haja a aprendizagem da leitura e da escrita em um sistema de escrita alfabético, é necessário que a criança faça a associação de um componente auditivo fonêmico a um componente visual gráfico. Como consequência, as habilidades metafonológicas em pré-escolares revelaram serem preditoras dos futuros bons leitores (Capellini \& Conrado, 2009; Germano \& Capellini, 2011). 
O leitor com problemas de aprendizagem manifesta dificuldade em identificar palavras e realizar a consciência fonológica, sendo que a avaliação da consciência fonológica é eficaz em identificar precocemente esses tipos de leitores (Scarborough, 1990). De acordo com os Parâmetros Curriculares Nacionais (PCNs) da Língua Portuguesa (Secretaria de Educação Fundamental, 1997) o ensino da Língua Portuguesa deve ser considerado em função do desenvolvimento das habilidades linguísticas básicas (falar, escutar, ler e escrever) e organizado em torno de dois eixos básicos: o uso da língua oral e escrita e a análise e reflexão sobre a língua, os quais devem ser desenvolvidos por escolares do ciclo I e II do Ensino Fundamental.

Desta forma, utilizar procedimentos de avaliação que permitam estabelecer e conhecer o perfil de aquisição e desenvolvimento das habilidades metafonológica é necessário, pois permite compreender as etapas de desenvolvimento destas habilidades e o impacto destas na aprendizagem da leitura e da escrita. Na realidade brasileira há vários estudos (Capovilla \& Capovilla, 2000; Capovilla, Smythe, Capovilla, \& Everatt, 2001; Cielo, 2002; Cunha \& Capellini, 2009; Moojen et al., 2003) que se propõem a apresentar e discutir tal perfil, entretanto, ainda são escassos, tanto na área da Educação como na área da Fonoaudiologia, estudos normatizados e validados que possam contribuir para uma visão sobre o desenvolvimento destas habilidades.

Para realizar uma avaliação efetiva, Vloedgraven e Verhoeven (2009) referiram que se deve respeitar a complexidade linguística, o tamanho de cada unidade de palavra, os alvos solicitados, os quais podem ser palavras, sílabas, onset (consoantes ou vogais ou agrupamentos de sons em posição inicial da sílaba), rimas (vogais e consoantes finais em posição final de sílaba) e fonemas (menor elemento constitutivo da cadeia falada que permite distinções semânticas). O tipo de operação cognitiva utilizada nestes testes pode ser: a identificação, a combinação, a segmentação e a manipulação de sílabas e/ou de fonemas. Um escolar pode identificar unidades fonológicas iguais ou diferentes dentro das palavras antes que eles consigam manipular estas mesmas unidades. Analogamente, os escolares podem adquirir a habilidade de combinar fonemas para formar palavras posteriormente a habilidade de segmentar palavras em fonemas.

O procedimento utilizado é composto por provas baseadas na revisão da literatura. Outro aspecto considerado foi o fato de que os sujeitos avaliados neste estudo foram selecionados a partir do $3^{\circ}$ ano do ensino fundamental. Isso ocorreu devido ao destaque dado pela literatura, de que, a consciência fonêmica se desenvolve simultaneamente à aprendizagem da escrita, colaborando com o processo de dominação das regras de conversão do grafema (símbolos usados para representar um conjunto de fonemas em um idioma determinado) ao fonema, desde os mais simples aos mais complexos (Lamprecht, 2004). Assim, com base nesses aspectos e na revisão de literatura, foi possível selecionar 12 provas para compor o instrumento deste estudo, como citado a seguir. As provas silábicas, tais como de Contagem de Sílabas (CgS), Síntese e Análise de Sílabas (SAS), Identificação de Sílabas (IS), Deleção de Sílabas (DS) e Combinação de Sílabas (CbS) foram selecionadas pois, de acordo com Ehri (1989), a aprendizagem da leitura em um sistema alfabético é feita pelo entendimento consciente, de que as palavras faladas podem ser quebradas em sons separados, sendo no nível de unidades maiores, como as sílabas, e, posteriormente no mais refinado nível do fonema. Otaiba, Puranik, Ziolkowski, e Montgomery (2009) ainda referiram que a síntese e análise silábica é uma das habilidades que não depende de instrução explícita, tanto que pré-escolares ou iletrados conseguem fazê-la. As habilidades de combinação de segmentos ao nível da palavra, ao nível silábico e ao nível fonêmico podem ser observadas em crianças a partir dos três anos de idade (Hayes \& Slater, 2008).

As prova de Rima (R) e Aliteração (A) foram selecionadas devido a serem relacionadas ao desenvolvimento da leitura. Estudos (Bradley \& Bryant, 1985; Goswami, 1988) revelam que a percepção de rima se desenvolve naturalmente por volta dos 4 ou 5 anos de idade, e são habilidades fonológicas iniciais que irão colaborar para o aparecimento da consciência fonêmica. Essa percepção da rima apresenta um efeito direto, contribuindo para a criança perceber que palavras podem compartilhar segmentos sonoros idênticos. A Aliteração, segundo Hayes e Slater (2008), pode ser observada em crianças por volta dos 18 meses de idade, sendo referido que as crianças já são capazes de identificar uma palavra ouvindo apenas a primeira sílaba. Esta atenção ao início da palavra é particularmente importante e ocorre devido às primeiras produções de fala (balbucio), pois constitui uma tentativa de se aproximar às pronúncias dos adultos (atenção à sequência e gestos articulatórios), seguidas da compreensão e segmentação das palavras da fala. Além disso, a aliteração favorece a percepção de que palavras podem ter o mesmo som no início (Chappell, Stephens, Kinnison, \& Pettigrew, 2009). A segmentação da palavra e a percepção dos contrastes fonológicos ocorrem por volta dos sete meses e meio de idade, possibilitando que a criança aos nove meses, atinja a capacidade de segmentar sílaba em onset, definida como consoantes ou vogais, ou agrupamentos de sons em posição inicial da sílaba (Hayes \& Slater, 2008).

As provas de Contagem de Fonemas (CgF), Síntese e Análise de Fonemas (SAF), Identificação de Fonemas (IF), Combinação de Fonemas (CbF) e Deleção de Fonemas (DF) foram selecionadas a partir dos estudos que indicaram que a habilidade de identificar fonemas favorece o entendimento do alfabeto, pois as letras representam de algum modo, fonemas (Torgensen \& Bryant, 1993). As provas de identificação de fonemas, contagem de fonemas ou deleção de fonemas, estariam relacionadas à alfabetização, já podendo ser observadas nas crianças com seis anos de idade, sendo que essas tarefas seriam difíceis para crianças de até cinco anos de idade (Bryant, Maclean, Bradley, \& Crossland, 1990). A habilidade de identificar fonemas no início, meio e fim e de segmentar fonema, favorece a per- 
cepção que esses fonemas podem ser tanto deletados das palavras formando uma nova palavra, como combinados para formar outra palavra (Chappell et al., 2009).

Posteriormente à escolha das provas, iniciou-se a escolha dos estímulos linguísticos que comporiam esse instrumento. Para a realização deste estudo, utilizamos a perspectiva fonológica, a qual compreende dois modelos principais que fornecem explicações para a estrutura da sílaba: o modelo linear e o modelo hierárquico, de acordo com a proposta de Câmera (1970a, 1970b) e Selkirk (1982). O procedimento de avaliação ele foi composto por palavras e figuras retiradas de bancos de palavras e figuras elaboradas para este estudo.

Ambos foram escolhidos de acordo com os princípios fonológicos da Língua Portuguesa, passando por critérios linguísticos de inclusão e exclusão de palavras (Capellini, Germano, \& Cardoso, 2008). As palavras foram extraídas do vocabulário escolar que consta do banco do Laboratório de Investigações dos Desvios da Aprendizagem (LIDA) / Universidade Estadual Paulista Júlio de Mesquita Filho (UNESP) - Marília/SP, composto por palavras extraídas dos livros de Língua Portuguesa de $1^{\circ}$ ao $4^{\mathrm{a}}$ séries do ensino fundamental, utilizados na Rede Municipal de Ensino (Germano \& Capellini, 2008). Este banco foi atualizado, sendo composto por palavras que foram extraídas dos livros de língua portuguesa de $1^{\circ}$ ao $6^{\circ}$ ano do Ensino Fundamental I e II, utilizados na Rede Municipal de Ensino da cidade de Marília/SP (Germano, 2011; Germano \& Capellini, 2008). Este banco contava com palavras de várias classes gramaticais, como pronomes, preposições, adjetivos, advérbios, verbos e substantivos. Como critérios de exclusão, visto que o instrumento tinha como objetivo o uso de figuras, foram excluídas as palavras que não pudessem ser representadas por figuras (pronomes, preposições, adjetivos, advérbios, verbos). Além disso, como critérios linguísticos para a exclusão de palavras do Português Brasileiro, considerou-se a "redução de sílabas" (Ex.: fósforo $>$ [fósfuru] [fosfru] $)$, "abertura e fechamento de vogais" (ex. bolacha [ô]/ bola [ó]); "Palavras com ditongo e hiato" (ex.: vai.da.de, va.i.da.de) e/ ou a "monotongação" (c[aj] xa, c[a]xa); "palavras com nasalidade" (ex.: órgão, falaram, homem); "tonicidade das vogais das sílabas" (seleção de palavras cujos alvos solicitados estivessem presentes na posição de sílaba tônica); "neutralização" (ex. p[e]pino $\sim$ p[i]pino); "vocalização da consoante" (palavras com /1/ pós-vocálico, realizado como consoante velar, pode mudar para /u/ assilábico ou /w/).

Como critério de inclusão foi selecionado apenas substantivos, que pudessem ser representados por figuras. $\mathrm{O}$ tipo de estímulo escolhido foi o visual (figuras de substantivos), a fim de fornecer o modelo de fonema ou de sílaba alvo para o avaliador e aliviar a sobrecarga de memória de trabalho fonológica para o escolar. As palavras selecionadas foram classificadas de acordo com a extensão da palavra (monossílabas, dissílabas, trissílabas e polissílabas) e colocadas em ordem alfabética. Além disso, buscamos utilizar palavras que tivessem os fonemas /b/, /p/,/t/, /d/, /k/, /g/, /f/, /v/, /s/, /z/, / J/, /3/, /l/ e /r/, de acordo com a aquisição da linguagem, a fim de possibilitar a avaliação dos mesmos nas provas do instrumento. Foram empregadas palavras monossílabas, dissílabas, trissílabas e polissílabas e considerou-se a abertura e fechamento das vogais, ou seja, a resposta manteve a abertura ou o fechamento de vogal compatível com a solicitação (evitar possíveis erros fonológicos, como por exemplo, foram excluídas palavras como "bolacha" [ô]/ "bola" [ó], "floresta" [é]/ "flores" [e]). Estes critérios foram adotados para que o escolar tivesse a compreensão de que todas as habilidades podem ocorrer independentemente do tamanho da palavra. A maioria das palavras empregadas do Português brasileiro apresentava a estrutura silábica simples, como consoante-vogal (ex.: tatu, boneca, pipa, vela, fogo), consoante-vogal-consoante (ex.: tartaruga, canguru, balde), consoante-consoante-vogal (ex.: chaminé).

No Brasil, há vários procedimentos com a proposta de avaliar as habilidades metafonológicas, como A Prova de Consciência Fonológica por Figuras (PCFF; Capovilla \& Capovilla, 2000), Perfil de Habilidades Fonológicas (PHF; Carvalho, Alvarez, \& Caetano, 1998), Protocolo de Tarefas de Consciência Fonológica (Cielo, 2002), Consciência fonológica: instrumento de avaliação sequencial (Moojen et al., 2003), Teste de Desempenho Cognitivo - Linguístico - versão individual do Teste (Smythe, Capellini, \& Silva, 2012), Provas de Habilidades Metalinguisticas e de Leitura (Cunha \& Capellini, 2009) de forma individual. O procedimento de avaliação elaborado neste estudo se diferencia dos demais, pelo fato do mesmo ser totalmente elaborado com figuras. Essa particularidade visa diminuir a sobrecarga de memória fonológica e, dessa forma, obter resultados fidedignos dos escolares nas diferentes faixas etárias e com diferentes tipos de problemas de aprendizagem. Além disso, este procedimento pode ser aplicado de forma coletiva, o que pode favorecer aos profissionais que atuam na área da saúde e da educação identificar por meio de rastreio as dificuldades metafonológicas de uma maneira rápida e precisa. Cabe ressaltarmos que a aplicação coletiva também auxilia o escolar realizar uma atividade de avaliação muito próxima da dinâmica vivenciada pelo mesmo em situação de sala de aula, oferecendo ao escolar avaliado mais autonomia e conforto para escrever e/ou expressar suas respostas.

Desta forma, este seria mais um instrumento importante, dada as suas especificidades e particularidades, para verificar o desempenho de escolares em testes de consciência fonológica que depende da complexidade linguística do teste elaborado, pois o mesmo contempla habilidades necessárias para verificar o mecanismo gerativo de memória de trabalho fonológica que outros procedimentos já publicados e disponíveis não contemplam em sua estrutura.

A partir dos estudos (Bradley \& Bryant, 1983; Capellini, Butarelli, \& Germano, 2010; Capellini et al., 2008; Cervera-Mérida \& Ygual-Fernández, 2003; Chard \& Dickson, 1999; Germano \& Capellini, 2011; Gombert, 2003; Hayes \& Slater, 2008; Manz et al., 2010) referidos na literatura nacional e internacional sobre a importância 
Germano, G. D. \& Capellini, S. A. (2015). Avaliação das Habilidades Metafonológicas (PROHFON): Caracterização e Comparação do Desempenho em Escolares.

das habilidades e o desenvolvimento da leitura, a hipótese deste estudo é de que o desempenho das habilidades metafonológicas melhora com a progressão da escolaridade. Com base nesta hipótese, o objetivo foi caracterizar e comparar o desempenho de escolares com bom desempenho acadêmico do $3^{\circ}$ ao $6^{\circ}$ ano do Ensino Fundamental I e II nas Provas de Habilidades Metafonológicas (PROHFON), a fim de verificar se houve progressão no desempenho dos escolares nas provas silábicas e fonêmicas com o aumento da escolaridade.

\section{Método}

Este estudo foi submetido e aprovado pelo Comitê de Ética em Pesquisa da Faculdade de Filosofia e Ciências (FFC/UNESP) - Marília/SP, sob número 1880/2008. Todos os responsáveis pelos escolares assinaram o Termo de Consentimento Livre e Esclarecido (TCLE).

\section{Participantes}

Participaram deste estudo um total de 169 escolares com bom desempenho acadêmico do $3^{\circ}$ ao $6^{\circ}$ ano do ensino fundamental, de ambos os gêneros, com faixa etária entre 7 e 13 anos de idade, matriculados em escola regular do município de Marília/SP. Os escolares foram divididos em: Grupo I (GI): 52 escolares do $3^{\circ}$ ano do Ensino Fundamental; Grupo II (GII): 51 escolares do $4^{\circ}$ ano do Ensino Fundamental; Grupo I (GIII): 42 escolares do $5^{\circ}$ ano do Ensino Fundamental; Grupo IV (GIV): 24 escolares do $6^{\circ}$ ano do Ensino Fundamental. Todos escolares participantes deste estudo apresentaram desempenho satisfatório (nota acima de 5,0) em dois bimestres consecutivos em provas de Língua Portuguesa e Matemática, segundo a indicação dos professores e prontuários escolares. Esses critérios são baseados no relatório do professor, previstos nos Relatórios Pedagógicos do SARESP (Secretaria da Educação do Estado de São Paulo, 2011). Neste estudo, foram considerados como critérios de exclusão dos participantes: escolares com deficiência sensorial, motora ou cognitiva e a não apresentação do Termo de Consentimento Livre e Esclarecido assinado pelos pais ou responsáveis. Como critérios de inclusão: escolares com Termo de Consentimento Livre e Esclarecido assinado pelos pais ou responsáveis e sem anotação referente à presença de deficiência sensorial, motora ou cognitiva, queixa auditiva, visual ou motora, constante em prontuário escolar.

\section{Procedimentos}

Os escolares foram submetidos à aplicação do procedimento de avaliação das habilidades metafonológicas (PROHFON) desenvolvido por Germano (2011) e descrito em Germano e Capellini (2011). A aplicação do procedimento foi realizada em grupos (com no máximo 20 escolares), regularmente matriculados em escola regular do município de Marília/SP. Antes de iniciar a aplicação do instrumento, a pesquisadora realizou uma reunião com a diretora e a coordenadora pedagógica da escola para apresentação do projeto original da pesquisa. A pesquisadora, após autorização para realização da pesquisa se direcionava para a sala de aula, solicitava a permissão do professor para a retirada dos escolares de sua sala e transferi-los até a sala de aula disponibilizada, onde foi realizada a coleta. A pesquisadora informava à professora a duração de tempo médio necessário para a aplicação do procedimento de avaliação. Caso algum escolar tivesse faltado naquele dia, o mesmo era convidado a participar no próximo dia de coleta. Já na sala da coleta, a pesquisadora solicitava aos escolares que sentassem em uma carteira, mantendo uma carteira vazia entre eles. Após se acomodarem, cada escolar recebia um "Caderno de Respostas", um lápis e uma borracha. A pesquisadora solicitou o preenchimento da folha de rosto do "Caderno de Resposta" com o nome, a série e a idade e, em seguida passava pelas carteiras conferindo se todos tinham preenchido. Somente após o preenchimento da folha, iniciou as instruções contidas no "Caderno de Questões" (avaliador).

Em seguida, foi realizada a leitura das instruções do "Caderno de Respostas" acompanhada pelos escolares. A pesquisadora ficou em posição visível à frente dos escolares e de posse de um "Caderno de Respostas". Conforme ia lendo as instruções da folha de rosto de seu caderno, a pesquisadora usava-o para demonstrar os exemplos contidos da folha de rosto do "Caderno de Resposta".

A pesquisadora deu início à aplicação do instrumento propriamente dito, a partir dos exemplos de cada prova. Os exemplos eram realizados juntamente dos escolares e, se houvesse necessidade, repetiam-se os exemplos e as explicações. Para cada pergunta foi dado um tempo para que os escolares escrevessem as respostas nos locais apropriados, passando para a pergunta seguinte. A pesquisadora orientou os escolares que só iria repetir a pergunta uma única vez. Após o término da aplicação, recolheu os cadernos, acompanhava os escolares até suas respectivas salas de aula, e dava início à seleção do próximo grupo. Esse processo foi repetido com os outros grupos de escolares até completar a amostra.

Os resultados foram realizados a partir da análise estatística, sendo utilizado o programa Statistical Package for Social Sciences (SPSS) 21.0 através da aplicação do teste de Kruskal-Wallis, com o intuito de verificar possíveis diferenças entre os quatro grupos estudados, quando comparados concomitantemente, para as variáveis de interesse. Também foi aplicado o teste de Mann-Whitney, ajustado pela Correção de Bonferroni, cujo objetivo foi identificar quais grupos diferenciaram-se entre si, quando comparados. Foi adotado o nível de significância de 5\% $(0,05)$, indicado por asterisco*.

\section{Resultados}

A Tabela 1 traz os resultados dos desempenhos dos grupos GI, GII, GIII e GIV em relação à média, desvio-padrão e valor de significância. 
Psicologia: Reflexão e Crítica, 28(2), 378-387.

Tabela 1

Resultados dos Desempenhos dos Grupos GI, GII, GIII e GIV em Relação à Média, Desvio-Padrão e Valor de Significância

\begin{tabular}{|c|c|c|c|c|c|c|c|}
\hline Variável & Grupo & $n$ & Média & Desvio-padrão & Percentil 25 & Percentil 75 & Valor de $p$ \\
\hline \multirow{5}{*}{$\mathrm{CgS}$} & I & 52 & 13,73 & 2,69 & 14,00 & 15,00 & \multirow{5}{*}{0,161} \\
\hline & II & 51 & 12,82 & 3,46 & 12,00 & 15,00 & \\
\hline & III & 42 & 14,14 & 1,54 & 14,00 & 15,00 & \\
\hline & IV & 24 & 14,29 & 1,37 & 14,00 & 15,00 & \\
\hline & Total & 169 & 13,64 & 2,63 & 13,00 & 15,00 & \\
\hline \multirow{5}{*}{$\mathrm{CgF}$} & $\mathrm{I}$ & 52 & 6,75 & 5,33 & 1,00 & 12,00 & \multirow{5}{*}{0,829} \\
\hline & II & 51 & 7,49 & 5,23 & 3,00 & 13,00 & \\
\hline & III & 42 & 7,62 & 5,04 & 2,75 & 12,00 & \\
\hline & IV & 24 & 7,33 & 5,41 & 2,00 & 13,00 & \\
\hline & Total & 169 & 7,27 & 5,21 & 2,00 & 12,00 & \\
\hline \multirow{5}{*}{ SAS } & $\mathrm{I}$ & 52 & 9,54 & 0,96 & 10,00 & 10,00 & \multirow{5}{*}{0,309} \\
\hline & II & 51 & 9,84 & 0,46 & 10,00 & 10,00 & \\
\hline & III & 42 & 9,81 & 0,55 & 10,00 & 10,00 & \\
\hline & IV & 24 & 9,63 & 0,97 & 10,00 & 10,00 & \\
\hline & Total & 169 & 9,71 & 0,75 & 10,00 & 10,00 & \\
\hline \multirow{5}{*}{ SAF } & I & 52 & 8,92 & 2,30 & 8,00 & 10,00 & \multirow{5}{*}{$0,002 *$} \\
\hline & II & 51 & 9,69 & 0,79 & 10,00 & 10,00 & \\
\hline & III & 42 & 8,86 & 1,87 & 9,00 & 10,00 & \\
\hline & IV & 24 & 9,58 & 1,21 & 10,00 & 10,00 & \\
\hline & Total & 169 & 9,23 & 1,73 & 9,00 & 10,00 & \\
\hline \multirow{5}{*}{ IS } & I & 52 & 12,87 & 3,28 & 12,25 & 15,00 & \multirow{5}{*}{0,256} \\
\hline & II & 51 & 13,57 & 1,88 & 12,00 & 15,00 & \\
\hline & III & 42 & 13,83 & 1,94 & 12,75 & 15,00 & \\
\hline & IV & 24 & 14,38 & 0,92 & 14,00 & 15,00 & \\
\hline & Total & 169 & 13,53 & 2,37 & 13,00 & 15,00 & \\
\hline \multirow{5}{*}{ IF } & I & 52 & 8,56 & 3,80 & 7,00 & 12,00 & \multirow{5}{*}{$0,001 *$} \\
\hline & II & 51 & 11,22 & 3,33 & 9,00 & 14,00 & \\
\hline & III & 42 & 10,98 & 3,21 & 8,00 & 14,25 & \\
\hline & IV & 24 & 9,96 & 2,48 & 8,25 & 11,75 & \\
\hline & Total & 169 & 10,16 & 3,51 & 8,00 & 13,00 & \\
\hline \multirow{5}{*}{$\mathrm{R}$} & I & 52 & 5,33 & 1,79 & 4,00 & 6,00 & \multirow{5}{*}{$<0,001^{*}$} \\
\hline & II & 51 & 5,84 & 1,93 & 5,00 & 7,00 & \\
\hline & III & 42 & 6,24 & 2,30 & 5,00 & 8,00 & \\
\hline & IV & 24 & 7,75 & 2,36 & 5,25 & 9,75 & \\
\hline & Total & 169 & 6,05 & 2,18 & 5,00 & 7,50 & \\
\hline \multirow{5}{*}{ A } & I & 52 & 6,10 & 3,03 & 4,00 & 8,00 & \multirow{5}{*}{$0,002 *$} \\
\hline & II & 51 & 7,71 & 3,05 & 5,00 & 10,00 & \\
\hline & III & 42 & 7,81 & 2,87 & 5,00 & 10,00 & \\
\hline & IV & 24 & 8,00 & 1,75 & 6,25 & 9,00 & \\
\hline & Total & 169 & 7,28 & 2,94 & 5,00 & 10,00 & \\
\hline
\end{tabular}


Germano, G. D. \& Capellini, S. A. (2015). Avaliação das Habilidades Metafonológicas (PROHFON): Caracterização e Comparação do Desempenho em Escolares.

\begin{tabular}{|c|c|c|c|c|c|c|c|}
\hline Variável & Grupo & $n$ & Média & Desvio-padrão & Percentil 25 & Percentil 75 & Valor de $p$ \\
\hline \multirow{5}{*}{ DS } & I & 52 & 12,13 & 3,61 & 11,00 & 15,00 & \multirow{5}{*}{0,107} \\
\hline & II & 51 & 13,76 & 2,41 & 13,00 & 15,00 & \\
\hline & III & 42 & 13,45 & 2,86 & 12,00 & 15,00 & \\
\hline & IV & 24 & 13,67 & 1,79 & 12,25 & 15,00 & \\
\hline & Total & 169 & 13,17 & 2,93 & 12,00 & 15,00 & \\
\hline \multirow{4}{*}{ DF } & I & 52 & 12,13 & 3,94 & 9,00 & 15,00 & \multirow{5}{*}{0,764} \\
\hline & II & 51 & 13,18 & 2,54 & 13,00 & 15,00 & \\
\hline & III & 42 & 13,14 & 2,62 & 12,00 & 15,00 & \\
\hline & IV & 24 & 13,08 & 2,59 & 11,25 & 15,00 & \\
\hline \multirow{6}{*}{$\mathrm{CbS}$} & Total & 169 & 12,83 & 3,07 & 12,00 & 15,00 & \\
\hline & I & 52 & 9,50 & 4,68 & 6,25 & 13,75 & \multirow{5}{*}{$<0,001^{*}$} \\
\hline & II & 51 & 12,92 & 2,96 & 12,00 & 15,00 & \\
\hline & III & 42 & 13,40 & 2,79 & 13,00 & 15,00 & \\
\hline & IV & 24 & 10,38 & 3,46 & 9,00 & 13,00 & \\
\hline & Total & 169 & 11,63 & 3,96 & 10,00 & 15,00 & \\
\hline \multirow{5}{*}{$\mathrm{CbF}$} & I & 52 & 7,67 & 4,95 & 3,00 & 12,00 & \multirow{5}{*}{$<0,001^{*}$} \\
\hline & II & 51 & 11,39 & 3,83 & 9,00 & 14,00 & \\
\hline & III & 42 & 10,83 & 3,73 & 8,75 & 14,00 & \\
\hline & IV & 24 & 8,13 & 4,13 & 5,00 & 11,00 & \\
\hline & Total & 169 & 9,64 & 4,51 & 7,00 & 14,00 & \\
\hline \multirow{5}{*}{ TS } & I & 52 & 56,54 & 14,19 & 48,00 & 67,00 & \multirow{5}{*}{$0,001^{*}$} \\
\hline & II & 51 & 62,92 & 7,97 & 59,00 & 69,00 & \\
\hline & III & 42 & 64,64 & 6,72 & 61,00 & 69,25 & \\
\hline & IV & 24 & 62,33 & 5,26 & 57,75 & 66,75 & \\
\hline & Total & 169 & 61,30 & 10,27 & 58,00 & 68,00 & \\
\hline \multirow{5}{*}{$\mathrm{TF}$} & I & 52 & 44,04 & 13,64 & 33,50 & 55,75 & \multirow{4}{*}{$0,003 *$} \\
\hline & II & 51 & 52,96 & 10,95 & 43,00 & 63,00 & \\
\hline & III & 42 & 51,43 & 11,16 & 43,00 & 58,75 & \\
\hline & IV & 24 & 48,08 & 8,50 & 42,25 & 55,75 & \\
\hline & Total & 169 & 49,14 & 12,10 & 42,00 & 58,00 & \multirow{6}{*}{$0,003 *$} \\
\hline \multirow{5}{*}{$\mathrm{T}$} & I & 52 & 113,23 & 26,83 & 93,75 & 132,00 & \\
\hline & II & 51 & 129,43 & 19,80 & 120,00 & 146,00 & \\
\hline & III & 42 & 130,12 & 19,20 & 118,00 & 143,00 & \\
\hline & IV & 24 & 126,17 & 13,25 & 119,75 & 138,50 & \\
\hline & Total & 169 & 124,15 & 22,45 & 112,00 & 142,00 & \\
\hline
\end{tabular}

Nota. Legenda: contagem de sílaba $(\mathrm{CgS})$ e de fonema $(\mathrm{CgF})$, síntese e análise de sílaba (SAS) e de fonema (SAF), identificação de sílaba (IS) e de fonema (IF), rima (R), aliteração (A), deleção de sílaba (DS) e de fonema (DF), combinação de sílaba (CbS) e de fonema $(\mathrm{CbF})$, total silábico (TS), total fonêmico $(\mathrm{TF})$ e total das provas $(\mathrm{T})$.

$* p<0,05$.

Na Tabela 1 pudemos observar que houve diferença estatisticamente significante entre os grupos GI, GII, GIII e GIV, nas provas de síntese e análise de fonema (SAF), identificação de fonema (IF), rima (R), aliteração (A), combinação de sílaba $(\mathrm{CbS})$ e de fonema $(\mathrm{CbF})$ e os totais silábicos (TS), fonêmicos (TF) e total da prova (T).

A Tabela 2 apresenta a comparação do desempenho entre os escolares dos quatro grupos avaliados, em relação às provas de habilidades metafonológicas. 
Tabela 2

Comparação do Desempenho entre os Escolares dos Quatro Grupos Avaliados, em Relação às Provas de Habilidades Metafonológicas

\begin{tabular}{|c|c|c|c|c|c|c|}
\hline \multirow{2}{*}{ Variável } & \multicolumn{6}{|c|}{ Par de Grupos } \\
\hline & I x II & I x III & I x IV & II x III & II x IV & III x IV \\
\hline $\mathrm{CgS}$ & 0,186 & 0,579 & 0,355 & 0,077 & 0,060 & 0,633 \\
\hline $\mathrm{CgF}$ & 0,469 & 0,408 & 0,526 & 0,892 & 0,887 & 0,941 \\
\hline SAS & 0,102 & 0,143 & 0,556 & 0,940 & 0,489 & 0,546 \\
\hline SAF & $0,002 *$ & 0,826 & 0,025 & $0,003 *$ & 0,886 & 0,024 \\
\hline IS & 0,609 & 0,131 & 0,107 & 0,274 & 0,185 & 0,892 \\
\hline IF & $<0,001 *$ & $0,003 *$ & 0,079 & 0,629 & 0,069 & 0,224 \\
\hline $\mathrm{R}$ & 0,091 & 0,016 & $<0,001^{*}$ & 0,283 & $0,001^{*}$ & 0,023 \\
\hline A & $0,004 *$ & $0,003 *$ & $0,001 *$ & 0,815 & 0,982 & 0,638 \\
\hline DS & 0,117 & 0,026 & 0,134 & 0,256 & 0,857 & 0,509 \\
\hline $\mathrm{DF}$ & 0,492 & 0,363 & 0,387 & 0,775 & 0,850 & 0,899 \\
\hline $\mathrm{CbS}$ & $<0,001^{*}$ & $<0,001^{*}$ & 0,711 & 0,184 & $0,001 *$ & $<0,001^{*}$ \\
\hline $\mathrm{CbF}$ & $<0,001^{*}$ & $0,002^{*}$ & 0,801 & 0,406 & 0,002 & 0,010 \\
\hline TS & 0,009 & $<0,001 *$ & 0,228 & 0,198 & 0,282 & 0,019 \\
\hline $\mathrm{TF}$ & $0,001^{*}$ & 0,011 & 0,314 & 0,470 & 0,040 & 0,165 \\
\hline $\mathrm{T}$ & $0,002 *$ & $0,002^{*}$ & 0,071 & 0,957 & 0,258 & 0,217 \\
\hline
\end{tabular}

Nota. Legenda: contagem de sílaba (CgS) e de fonema (CgF), síntese e análise de sílaba (SAS) e de fonema (SAF), identificação de sílaba (IS) e de fonema (IF), rima (R), aliteração (A), deleção de sílaba (DS) e de fonema (DF), combinação de sílaba (CbS) e de fonema $(\mathrm{CbF})$, total silábico $(\mathrm{TS})$, total fonêmico $(\mathrm{TF})$ e total das provas $(\mathrm{T})$. Alfa de Bonferroni $=0,008512 . *$ Valores significativos $(p \leq 0,05)$.

Os resultados da Tabela 2 indicaram que houve diferença estatisticamente significante na comparação entre os escolares do GI e GII nas provas de síntese e análise fonêmica (SAF), identificação de fonema (IF), aliteração (A), combinação de sílaba (CbS) e de fonema (CbF), total fonêmico (TF) e total das provas (T). Desse modo, quando observamos as habilidades em relação à progressão da escolaridade, verificamos que a habilidade de síntese e análise fonemica (SAF), identificação de fonema (IF), aliteração (A), combinação de sílaba (CbS) e de fonema $(\mathrm{CbF})$ foram adquiridas e, posteriormente sistematizadas entre o $3^{\circ}$ e $4^{\circ}$ ano (comparação GI x GII).

Na comparação entre os escolares do GI e GIII, houve diferença estatisticamente significante nas provas de identificação de fonema (IF), aliteração (A), combinação de sílaba (CbS) e de fonema (CbF), total silábico (TS) e total das provas (T), sendo que o desempenho do GI foi inferior ao do GIII, evidenciando que houve melhora da aquisição das habilidades mencionadas em relação ao aumento da escolaridade.

Na comparação entre os grupos GI e GIV, observou-se diferença estatisticamente significante nas provas de rima
(R) e aliteração (A). Para essa comparação, observamos que a habilidade de rima foi adquirida apenas tardiamente, ou seja, a diferença entre os desempenhos só ocorreu quando os escolares dos grupos GI e GII (Ensino Fundamental I) foram comparados com os escolares de GIV (Ensino Fundamental 2; não houve diferença estatisticamente significante nas comparações GI x GIV e GII x GIV para as provas de rima e aliteração). Na comparação entre os grupos GII e GIII, observou-se diferença estatisticamente significante na prova de síntese e análise fonêmica (SAF), indicando que as habilidades foram adquiridas e, posteriormente sistematizadas entre o $3^{\circ}$ e $4^{\circ}$ ano (comparação GI x GII). Na comparação entre os grupos GII e GIV, observou-se diferença estatisticamente significante nas provas de rima $(\mathrm{R})$ e combinação de sílaba $(\mathrm{CbS})$ e fonema $(\mathrm{CbF})$.

Na comparação entre os grupos GIII e GIV, observou-se diferença estatisticamente significante na prova de combinação de sílaba (CbS), evidenciando que houve melhora na aquisição das habilidades mencionadas, em relação ao aumento da escolaridade, tanto na comparação entre GII e GIV, como na comparação de GIII e GIV. 
Germano, G. D. \& Capellini, S. A. (2015). Avaliação das Habilidades Metafonológicas (PROHFON): Caracterização e Comparação do Desempenho em Escolares.

A Tabela 3 traz os valores de percentil 25 e 75 , os quais foram utilizados para a classificação dos grupos GI, GII, GIII e GIV, em relação às provas metafonológicas.
A classificação foi realizada "sob atenção" referente ao desempenho abaixo do valor do percentil 25 (exclusive) e "Esperado" - para os valores acima do valor do percentil 25 (inclusive).

Tabela 3

Valores de Percentil 25 e 75 e Classificação de GI, GII, GIII e GIV em Relação às Provas Metafonológicas

\begin{tabular}{ccccccccc}
\hline \multirow{2}{*}{ Variável } & \multicolumn{2}{c}{$3^{\circ}$ ANO } & \multicolumn{2}{c}{$4^{\circ}$ ANO } & \multicolumn{2}{c}{$5^{\circ}$ ANO } & \multicolumn{2}{c}{$6^{\circ}$ ANO } \\
\cline { 2 - 9 } & SA & E & SA & E & SA & E & SA & E \\
\hline CgS & $0-13$ & $14-15$ & $0-11$ & $12-15$ & $0-13$ & $14-15$ & $0-13$ & $14-15$ \\
CgF & $0-1$ & $2-15$ & $0-2$ & $3-15$ & $0-2$ & $3-15$ & $0-1$ & $2-15$ \\
SAS & $0-9$ & 10 & $0-9$ & 10 & $0-9$ & 10 & $0-9$ & 10 \\
SAF & $0-8$ & $8-10$ & $0-9$ & 10 & $0-8$ & $8-10$ & $0-9$ & 10 \\
IS & $0-11$ & $12-15$ & $0-11$ & $12-15$ & $0-11$ & $12-15$ & $0-13$ & $14-15$ \\
IF & $0-6$ & $7-15$ & $0-8$ & $9-15$ & $0-7$ & $8-15$ & $0-8$ & $9-15$ \\
R & $0-3$ & $4-10$ & $0-4$ & $5-10$ & $0-4$ & $5-10$ & $0-5$ & $6-10$ \\
A & $0-3$ & $4-10$ & $0-4$ & $5-10$ & $0-4$ & $5-10$ & $0-6$ & $7-10$ \\
DS & $0-11$ & $12-15$ & $0-12$ & $13-15$ & $0-11$ & $12-15$ & $0-12$ & $12-15$ \\
DF & $0-8$ & $9-15$ & $0-12$ & $13-15$ & $0-11$ & $12-15$ & $0-11$ & $12-15$ \\
CbS & $0-6$ & $7-15$ & $0-11$ & $12-15$ & $0-12$ & $13-15$ & $0-8$ & $9-15$ \\
CbF & $0-2$ & $3-15$ & $0-8$ & $9-15$ & $0-8$ & $9-15$ & $0-4$ & $5-15$ \\
TS & $0-47$ & $48-70$ & $0-58$ & $59-70$ & $0-60$ & $61-70$ & $0-57$ & $58-70$ \\
TF & $0-33$ & $34-70$ & $0-42$ & $43-70$ & $0-42$ & $43-70$ & $0-42$ & $43-70$ \\
T & $0-93$ & $94-160$ & $0-121$ & $122-160$ & $0-117$ & $118-160$ & $0-119$ & $120-160$ \\
\hline
\end{tabular}

Nota. Legenda: contagem de sílaba $(\mathrm{CgS})$ e de fonema $(\mathrm{CgF})$, síntese e análise de sílaba (SAS) e de fonema (SAF), identificação de sílaba (IS) e de fonema (IF), rima (R), aliteração (A), deleção de sílaba (DS) e de fonema (DF), combinação de sílaba (CbS) e de fonema $(\mathrm{CbF})$, total silábico (TS), total fonêmico $(\mathrm{TF})$ e total das provas $(\mathrm{T})$. SA: sob-atenção; E: esperado.

\section{Discussão}

Os escolares deste estudo não apresentaram dificuldades em relação a maioria das habilidades silábicas (contagem de sílaba, síntese e análise, identificação, deleção e combinação). Já em relação às habilidades fonêmicas, os escolares apresentaram dificuldades na maioria das provas, com exceção das provas de identificação, deleção e combinação. Isto demonstrou que com a progressão da escolaridade, os escolares do GI ao GIV, apresentaram aumento do número de acerto nestas habilidades, principalmente as silábicas, mas o mesmo não ocorreu com as habilidades fonêmicas. Os resultados deste estudo demonstraram que os escolares, independente da seriação escolar, apresentaram dificuldades nas habilidades fonêmicas de contagem, de síntese e análise e na habilidade suprassegmental (rima); sendo que para essas habilidades, os escolares não apresentaram melhora de seus desempenhos mesmo com o aumento da escolaridade. Por definição, a rima representa unidades denominadas unidades intra-silábicas e, em termos de tamanho, ficariam entre a sílaba e fonemas finais (Antony \& Francis, 2005; Bryant et al., 1990). Assim, os autores referiram que a habilidade de rima é uma das primeiras habilidades metafonológicas a ser desenvolvida, ocorrendo antes mesmo da alfabetização, ao longo do desenvolvimento da fala na oralidade. Além disso, o desenvolvimento dessa habilidade irá impactar a aprendizagem da leitura e escrita, pois constituem a base para a leitura e a escrita. Assim, quanto mais sensível a criança for aos componentes dos sons (sílabas, rimas, fonemas), melhor leitora ela será, independentemente da inteligência, recepção de vocabulário, habilidades de memória e classe social (Antony \& Francis, 2005; Bryant et al., 1990).

Os resultados deste estudo indicaram que os escolares apresentaram dificuldades nas habilidades de síntese e análise fonêmica, contagem de fonema e rima, sendo que essa dificuldade de percepção do menor segmento da fala 
continuou, mesmo com o aumento da seriação (do $3^{\circ}$ ao $5^{\circ}$ ano). As habilidades de contagem de fonema e síntese e análise de fonema estão relacionadas ao período de alfabetização, o que não ocorre com a habilidade de rima, a qual deve ser adquirida antes mesmo do ingresso na escola (Bryant et al., 1990; Gray \& McCutchen, 2006). A aquisição dessas habilidades fonêmicas e de rima favorecem o entendimento do alfabeto, pois as letras representam de algum modo fonemas (Torgensen \& Bryant, 1993). A percepção do fonema possibilita que o escolar faça a associação grafema-fonema, e perceba que os fonemas podem ser combinados para formar outra palavra, contribuindo, assim, para o mecanismo gerativo de memória, que converte a fonologia em ortografia (Chappell et al., 2009). Este mecanismo dará condições à criança para que ela leia qualquer palavra nova, apesar de cometer erros em palavras irregulares.

Apesar de vários autores, como Cervera-Mérida e Ygual-Fernández (2003), Chard e Dickson (1999) e Manz et al. (2010) referirem que as habilidades metafonológicas se desenvolvem num continuum, que evolui a partir da habilidade da rima até as habilidades mais complexas (combinação e segmentação de sílabas e de fonemas). Observamos neste estudo, que os escolares, independente da seriação, tiveram dificuldades em desenvolver desde as habilidades mais primitivas, tais como a rima e a aliteração, até as mais complexas (deleção e combinação), mesmo com o aumento da escolaridade. Haase (1990) e Lamprecht (2004) referiram que, sem a oportunidade de acesso à instrução direta, a consciência fonológica não é adquirida por aproximadamente $25 \%$ dos estudantes da primeira série do ensino fundamental de classe média, podendo acarretar dificuldades na aprendizagem da leitura e da escrita. Esses achados não corroboram com o referido na literatura científica nacional e internacional e aos PCNs (Secretaria de Educação Fundamental, 1997). Os PCNs, utilizados nas escolas brasileiras, fizeram referência de que a capacidade cognitiva tem grande influência na postura do indivíduo em relação às metas que quer atingir nas mais diversas situações da vida. Assim, de acordo com o mesmo, a língua é um sistema que se estrutura no uso e para o uso, escrito e falado, sempre contextualizado. Entretanto, a condição básica para o uso escrito da língua, que é a apropriação do sistema alfabético, envolve, da parte dos alunos, aprendizados muito específicos relativos aos componentes do sistema fonológico da língua e às suas inter-relações. $\mathrm{O}$ desenvolvimento das capacidades linguísticas de ler e de escrever não acontece espontaneamente; precisa ser ensinado sistematicamente.

Contudo, deve-se atentar para o fato de que muitos alunos têm na escola sua principal fonte de contato com a linguagem escrita, e considerando que muitos professores, quando utilizam as metodologias atuais de alfabetização, não enfocam procedimentos de correção e ensino eficazes da escrita, estes acabam por manter os alunos em situação de desconhecimento da ortografia, conforme referido por Massi e Berberian (2005). Assim, muitos escolares, em fase inicial de alfabetização, podem apresentar alterações na leitura e escrita em decorrência da escola não enfatizar o ensino da ortografia, pela frágil fundamentação teórica e pratica de seus educadores (Capellini et al., 2010; Germano \& Capellini, 2011).

Com base no exposto, talvez possamos explicar o fato dos escolares deste estudo apresentarem dificuldades na realização das provas metafonológicas elaboradas para este estudo, pois quando o princípio alfabético da Língua Portuguesa não é ensinado sistematicamente no contexto de sala de aula, os escolares em fase de desenvolvimento da leitura e escrita podem e vão apresentar falhas em habilidades de detectar, discriminar, comparar e memorizar sons e silabas, conforme os achados encontrados neste estudo; o que pode acarretar dificuldade no acionamento do mecanismo gerativo para a formação de palavras para a leitura e escrita (Germano \& Capellini, 2011).

\section{Conclusão}

A partir dos achados desse estudo, foi possível concluir que houve melhora no desempenho dos escolares, quando comparados os desempenhos do $3^{\circ}$ ao $6^{\circ}$ ano para a maioria das habilidades silábicas (contagem de sílaba, síntese e análise, identificação, deleção e combinação) e para algumas habilidades fonêmicas (identificação, deleção e combinação). Os escolares dos grupos GI, GII, GIII e GIV, apresentaram dificuldades principalmente nas habilidades fonêmicas de contagem, de síntese e análise e de rima.

Sendo assim, o PROHFON pode vir a ser um instrumento de auxílio tanto os profissionais da saúde quanto os da educação, no estabelecimento do perfil de habilidades e dificuldades em habilidades metafonológicas, o que pode contribuir futuramente para uma melhor compreensão entre estas habilidades e o desenvolvimento da leitura e da escrita em escolares em fase de alfabetização. Este instrumento também contribuiu para verificar que, não foram todas as habilidades metafonológicas que os escolares deste estudo apresentaram domínio durante o avanço na escolarização; isto porque quando estas habilidades não são trabalhadas sob controle de instrução formal em situação de sala de aula, os escolares não dominam competências necessárias para a aquisição do principio alfabético da Língua Portuguesa.

\section{Referências}

Antony, J. L., \& Francis, D. (2005). Development of phonological awareness. Current Directions in Psychological Science, 14(5), 255-259. doi:10.1177/0022219409335218

Bradley, L., \& Bryant, P. E. (1983). Categorizing sounds and learning to read - A casual connection. Nature, 301, 419-421. doi:10.1038/301419a0

Bradley, L., \& Bryant, P. E. (1985). Rhyme and reason in reading and spelling. Ann Arbor, MI: University of Michigan Press.

Bryant, P. E., Maclean, M., Bradley, L. L., \& Crossland, J. (1990). Rhyme and alliteration, phoneme detection, and learning to read. Developmental Psychology, 26(3), 429-438. doi:10.1037/0012-1649.26.3.429

Câmera, J. R. (1970a). Estrutura da Língua Portuguesa. Petrópolis, RJ: Vozes. 
Germano, G. D. \& Capellini, S. A. (2015). Avaliação das Habilidades Metafonológicas (PROHFON): Caracterização e Comparação do Desempenho em Escolares.

Câmera, J. R. (1970b). Problemas de linguística descritiva (3. ed.). Petrópolis, RJ: Vozes.

Capellini, S. A., Butarelli, A. P. K. J., \& Germano, G. D. (2010). Dificuldades de aprendizagem da escrita em escolares de $1^{\text {a }}$ a $4^{\mathrm{a}}$ séries do ensino público. Revista Educação em Questão, 37(23), 146-164. Recuperado em http://www.periodicos.ufrn. br/educacaoemquestao/article/view/3981/3248

Capellini, S. A., \& Conrado, T. L. B. C. (2009). Desempenho de escolares com e sem dificuldades de aprendizagem de ensino particular em habilidade fonológica, nomeação rápida, leitura e escrita. Revista CEFAC, 11(Supl. 2), 183-193. doi:10.1590/ S1516-18462009005000002

Capellini, S. A., Germano, G. D., \& Cardoso, A. C. (2008). Relação entre habilidades auditivas e fonológicas com crianças com dislexia do desenvolvimento. Psicologia Escolar e Educacional, 12(1), 235-253. doi:10.1590/S141385572008000100016

Capovilla, A. G. S., \& Capovilla, F. C. (2000). Efeitos do treino de consciência fonológica em crianças com baixo nível sócio-econômico. Psicologia: Reflexão e Crítica, 13(1), 1-28. doi:10.1590/S0102-79722000000100003

Capovilla, A. G. S., Smythe, I., Capovilla, F. C., \& Everatt, J. (2001). Adaptação brasileira do International Dyslexia Test: Perfil cognitivo de crianças com escrita pobre. Temas sobre Desenvolvimento, 10(57), 30-37.

Carvalho, I. A., Alvarez, A. M., \& Caetano, A. L. (1998). Perfil de habilidades fonológicas. São Paulo, SP: Via Lettera.

Cervera-Mérida, J. F., \& Ygual-Fernández, A. (2003). Intervención logopédica em los trantornos fonológicos desde el paradigma psicolinguístico del procesamiento del habla. Revista de Neurología, 36(Supl. 1), S39-S53. Recuperado em http://www.neurologia.com/pdf/Web/36S1/os10039.pdf

Chappell, J., Stephens, T., Kinnison, L., \& Pettigrew, J. (2009). Educational diagnosticians' understanding of phonological awareness, phonemic awareness, and reading fluency. Assessment for effective intervention, 35(1), 24-33. doi:10.1177/1534508409331653

Chard, J., \& Dickson, V. (1999). Phonological awareness: Instrucional and assessment guidelines. Interventionin School and Clinic, 34(5), 261-215. doi:10.1177/105345129903400502

Cielo, C. A. (2002). Habilidades em consciência fonológica em crianças de 04 a 08 anos de idade. Pró-Fono, 14, 287-478.

Cunha, V. L. O., \& Capellini, S. A. (2009). PROHMELE. Provas de Habilidade Metalinguisticas e de Leitura. Rio de Janeiro, RJ: Revinter.

Ehri, L. C. (1989). The development of spelling knowledge and its role in reading acquisition and reading disability. Journal of Learning Disabilities, 22(6), 356-365. doi:10.1177/002221948902200606

Germano, G. D. (2011). Instrumento de avaliação metafonológica para caracterização de escolares com dislexia, transtorno e dificuldades de aprendizagem (Tese de doutorado, Faculdade de Filosofia e Ciência, Universidade Estadual Paulista Júlio de Mesquita Filho, Marília, SP, Brasil).

Germano, G. D., \& Capellini, S. A. (2008). Eficácia do programa de remediação auditivo-visual computadorizado em escolares com dislexia. Pró-Fono, 20(4), 237-242. doi:10.1590/s010456872008000400006

Germano, G. D., \& Capellini, S. A. (2011). Desempenho de escolares com dislexia, transtornos e dificuldades de aprendizagem em provas de habilidades metafonológicas (PROHFON) Jornal da Sociedade Brasileira de Fonoaudiologia, 23(2), 135-141. doi:10.1590/S2179-64912011000200010

Gombert, J. E. (2003). Atividades metalinguísticas e aquisição da leitura. In M. R. Maluf(Ed.), Metalinguagem e aquisição da escrita (pp. 19-64). São Paulo, SP: Casa do Psicólogo,

Goswami, U. (1988). Children's use of analogy in learning to spell. British of Developmental Psychology, 6(1), 21-34. doi:10.1111/j.2044-835x.1988.tb01077.x

Gray, A., \& McCutchen, D. (2006). Young readers'use of phonological information: Phonological awareness, memory, and comprehension. Journal of Learning Disabilities, 39(4), 325-333. doi:10.1177/00222194060390040601

Haase, V. G. (1990). Consciência fonêmica e neuromaturação (Dissertação de mestrado em Linguística Aplicada, Pontifícia Universidade Católica do Rio Grande do Sul, Porto Alegre, RS, Brasil).

Hayes, R., \& Slater, A. (2008). Three month-olds'detection of alliteration in syllables. Infant Behavior \& Development, 31(1), 153-156. doi:10.1016/j.infbeh.2007.07.009

Lamprecht, R. R. (Ed.). (2004). Aquisição fonológica do português: Perfil de desenvolvimento e subsídios para a terapia. Porto Alegre, RS: Artmed.

Manz, P., Hughs, C., Barnabas, E., \& Bracaliello, C. (2010). A descriptive review and meta-analysis of family-based emergent literacy interventions: To what extent is the research applicable to low-income, ethnic-minority or linguistically-diverse young children? Early Childhood Research Quarterly, 5(4), 409-431. doi:10.1016/j.ecresq.2010.03.002

Massi, G. A., \& Berberian, A. P. (2005). A clínica fonoaudiológica voltada aos chamados distúrbios de leitura e escrita: Uma abordagem constitutiva da linguagem. Revista da Sociedade Brasileira de Fonoaudiologia, 10(1), 43-52.

Moojen, S., Lamprecht, R., Santos, R. M., Freitas, G. M., Broadcz, R., Siqueira, M., ...Guarda, E. (2003). Confias- Consciência fonológica: Instrumento de avaliação sequencial. São Paulo, SP: Casa do Psicólogo.

Otaiba, S., Puranik, C., Ziolkowski, R., \& Montgomery, T. (2009). Effectiveness of early phonological awareness interventions for students with speech or language impairments. The Journal of Special Education, 43(2), 107-128. doi:10.1177/0022466908314869

Scarborough, H. S. (1990). Very early language deficits in dyslexic children. Child Development, 61(6), 1728-1743. doi: $10.2307 / 1130834$

Secretaria da Educação do Estado de São Paulo. (2011). Relatório Pedagógico 2011 Saresp. Língua Portuguesa. Recuperado em http://saresp.fde.sp.gov.br/2011/Pdf/Relat\%C3\%B3rio Pedag\%C3\%B3gico_L\%C3\%ADngua_Portuguesa_2011.pdf

Secretaria de Educação Fundamental. (1997). Parâmetros curriculares nacionais: Língua Portuguesa. Brasília, DF: Autor.

Selkirk, E. O. (1982). The syllable. In F. V. Huslt \& N. Smith (Eds.), The structure of phonological representations (Vol. 2, pp. 337-383). Dordrecht, Holland: Foris

Smythe, I., Capellini, S. A., \& Silva, C. (2012). Protocolo de avaliação de habilidades cognitivo-linguisticas. Marília, SP: Fundação para o Desenvolvimento do Ensino, Pesquisa e Extensão.

Torgensen, J. K., \& Bryant, B. R. (1993). Test of phonological awareness. Austin, TX: Pro-Ed.

Vloedgraven, J., \& Verhoeven, L. (2009). The nature of phonological awareness throughout the elementary grades: An item response theory perspective. Learning and Individual Differences, 19(2), 161-169. doi:10.1016/j.lindif.2008.09.005

Recebido: 04/10/2013 $I^{a}$ revisão: $15 / 12 / 2013$ $2^{a}$ revisão: $23 / 03 / 2014$ Aceite final: 08/05/2014 